SIR NORMaN LOCKYER, K.C.B., F.R.S.

LADY LOCKYER.

DR. LOCKYER,

$\bar{M}$, Maccoll.

Prof. R. MEldola, F.R.S.

Sir A. Noble, Bart., K.C.B., F.R.S.

Sir Gilbert Parker, M.P.

Prof. Perry, F.R.S.

Sir William Ramsay, K.C.B., F.R.S.

THE LORD REAY, G.C.S.I.

Sir Wemyss Reid.

Sir William Richmond, K.C.B., R.A.

Mr. E. Robertson, M.P.

SiR HENRY ROSCOE, F.R.S.

SIR A. RÜCKER, F.R.S.

DR. W. N. SHAW, F.R.S.

Mr. Alex Siemens.

The Lord Strathcona and Mount Royal.

Sir L. Alma Tadema, R.A.

Prof. Silvanus P. Thompson, F.R.S

DR. A. D. WALLER, F.R.S.

Field Marshal Viscount Wolseley, G.C.B.

Sir Henry Trueman Wood.

\section{NEW REGULATIONS OF THE BOARD OF EDUCATION.}

$\mathrm{NO}$ system of national education is complete which fails to recognise the essential importance of the work of the satisfactory secondary school. Its importance, that is, both as providing a means by which the exceptionally well endowed boys and girls of the elementary schools may continue their education under better conditions, and also as affording an adequate preparation for those pupils who later will become technical students and university undergraduates, or who will without further instruction enter upon the active duties of life. The recent Education Act gave an official recognition to what has long been urged by those who understand our educational needs, that true education from beginning to end is an organic whole. The duty has, in fact, been laid upon the Board of Education of superintending and promoting the supply by local education authorities of education other than elementary. The Board is now the final court of appeal in all matters pertaining to the administration of secondary education.

It is considerations such as these which lead us to regard the regulations ${ }^{1}$ recently issued by the Board of Education for the government and administration of English secondary education as one of the most important of the educational documents of recent years. For, since the Board is in a position to reward by substantial grants. a due adherence to the regulations here formulated, it is clear that the principles advocated officially will, whether they are right or wrong, exercise a profound influence upon the curriculum and ideals of the schools.

Such being the case, it is gratifying to find that on the whole the regulations are framed on broad and liberal lines, though, as we shall have occasion to indicate, there are dangers which it is imperative those in authority should avoid, and indications that the claim of instruction in scientific method to a place in every stage of education may be disregarded if certain phrases in the regulations are followed too literally.

It will serve to give a clearer idea of the influence the regulations are likely to exert if an attempt is made first to review some of the definitions put forward in the official publication. A secondary school is described as

" any Day or Boarding School which offers to each of its scholars, up to and beyond the age of sixteen, a general

1 "Regulations for Secondary Schools (from August 1, rgo4, to July $3 \mathrm{r}$, roo5)." [Cd. 2128.] Price 2 $d$.

NO. I 8 I 5 , voI. 70$]$ education, physical, mental and moral, given through a complete graded course of instruction of wider scope and more advanced degree than that given in Elementary Schools."

Explaining what should be the characteristics of a secondary school course of instruction, the prefatory memorandum to the regulations states that it should be general, complete, and graded in its various branches. The explanation as to the precise meaning to be attached to the description " general " deserves - both because of its fairness and catholicity-to be quoted in full :-

"The instruction must be general; i.e. must be such as gives a reasonable degree of exercise and development to the whole of the faculties, and does not confine this development to a particular channel, whether that of pure and applied Science, or literary and linguistic study, or of that kind of acquirement which is directed simply at fitting a boy or girl to enter business in a subordinate capacity with some previous knowledge of what he or she will be set to do. A Secondary School should keep in view the development and exercise of all the faculties involved in all these different kinds of training, and will fail to give a sound general education to its scholars in so far as it sends them out, whether to further study or to the business of life, with one or other of these faculties neglected, or with one developed at the expense of the rest. Specialisation in any of these directions should only begin after the general education has been carried to a point at which the habit of exercising all these faculties has been formed and a certain solid basis for life has been laid in acquaintance with the structure and laws of the physical world, in the accurate use of thought and language, and in practical ability to begin dealing with affairs."

Secondary education such as is outlined in this paragraph will meet with the approval of every man of science. Education conducted on scientific lines is that which gives a " reasonable degree of exercise and development to the whole of the faculties." If the Board takes care that in interpreting its regulations in the schools the inspectors strive to secure this allround, healthy mental development of English boys and girls, the hearty cooperation and sympathy of men of science may be depended upon. For to ensure the exercise and development of all the faculties, a training in experimental science is necessary, just as a course in literary and linguistic studies is essential. As the quotation shows, the Board of Education is aware that for a complete education many studies are required, each with its own object and special work. It is important to bear in mind also that the main groups of studies cooperating for the complete education of the child are of equal importance. Just as the study of literature and language can promote the growth of and strengthen some faculties to which practical studies are unable to appeal, so a training in experimental science is the best and only means of ensuring the healthy unfolding of other sides of the human brain. The classical scholar ignorant of the laws and phenomena of nature is an uneducated man, just as is a man of science who has no knowledge of the literature of his own and other countries.

This view of true education is admirably set forth in the statement prepared by the president of the British Association, and revised by a committee including the deputy Vice-Chancellor of the University of Oxford, the Vice-Chancellor of the University of Cambridge, and representatives of the modern English universities, for presentation to the Prime Minister by the recent deputation which waited upon him with reference to increased State aid for university education.

"The men upon whom the nation must chiefly depend for aid under the complex conditions of the modern world must not be entirely untrained in the study of the nature and causes of the things which surround them, or of the 
forces which have to be utilised in our daily life; their training and education in humanities must also have been of the widest.

"Such men cannot be produced either by a university which neglects science or by a technical college which neglects the humanities.

"Hence the universities must be enabled to combine these two sides of a complete education, and they must also be enabled to foster research along both lines, for research is the highest and most important instrument of education, as well as its most valuable result."

And what is true of higher education is true also of secondary education upon which it rests.

It is desirable thus to recapitulate these important truths in view of section viii. of the memorandum. This paragraph is likely to lead to misapprehension and to create doubts in the minds of some men of science as to how much of the declaration of faith quoted with approval above is to be regarded as more than the mere expression of a pious hope. Section viii. informs us that all types of secondary schools fall into three main classes, and that in respect of the kind of education they offer they may be discriminated roughly as the literary, the scientific, and the commercial types of school. The boys from the literary, or first-grade school-the section goes on to explain-proceed to the university; the boys of the scientific, or second-grade school, are educated to the age of eighteen or nineteen but do not proceed to the university; the boys of the commercial, or third-grade school, leave at sixteen years of age and go into business and commerce, train to become teachers, or proceed into technical and industrial pursuits. The objects of these schools as set forth in this extraordinary paragraph must be placed before the reader :-

"The first of these paying special regard to the development of the higher powers of thought and expression, and that discriminating appreciation of what is best in the thought and art of the world, in other ages and countries as well as in our own, which forms the basis of all human culture; the second, to the training of the intellect towards understanding and applying the laws of the physical universe; and the third, to the equipment of the scholars for practical life in the commercial and industrial community of which they are members."

After studying this section one is led to believe that it has crept in by mistake; it may safely be said to have been written by somebody other than the author of the definition of general secondary education given earlier. Here we detect the old pestilent heresy that culture is the prerogative of the classical man alone, and that "a discriminating appreciation of what is best in the thought and art of the world " is forever impossible to boys from first- and second-grade schools. If the secondary education in all types of school is to give " a reasonable degree of exercise and development to the whole of the faculties," why are not all boys and girls-whether they leave school at sixteen or eighteen -each in their degree cultured?

The future in life allotted in this section to the products of each grade of school is equally preposterous. The paragraph makes it appear as if all the useful work of the world is done by people who leave school at sixteen, and as if all university men spend their lives in indulging their "discriminating appreciation of what is best in the thought and art of the world."

As readers of Nature at least know, the sorry figure this country has cut recently in the industrial competition of the nations, and in another direction in South Africa, is precisely because of the disposition in times past, on the part of those responsible for English education, to regard "the training of the intellect towards understanding and applying the laws of the physical universe" as the work of some special kind of school instead of being a necessary and important NO. I 8 I 5 , VOL. 70] part of every grade of education. It is surely time that it was recognised on all hands that " practical life in the commercial and industrial community" needs and deserves as good and careful an education on the part of those who pursue it as any other sphere of human activity. But, as we have said, this maladroit section viii. is an incongruity so far as the regulations as a whole are concerned, and we trust the inspectors may be instructed to ignore it.

To turn to the question of the grants to be awarded to secondary schools recognised as efficient by the Board of Education. As the sum is limited which Parliament at present places at the disposal of the Board for grants in aid of education other than elementary, the grants payable under the new regulations are to be made in respect of a four years' course only. The average age of the scholars in any class commencing the course must not be less than twelve years. The earlier education leading up to this course, and the further education, if any, given beyond it, are to be regarded as forming together with it a single organic and progressive system. Subject to certain conditions, a grant will be paid on account of each scholar attending the approved course in accordance with the new regulations on the following scale:-in the first year of the course, $40 s$.; in the second, $60 s$. ; in the third, 8os.; and in the fourth, roos.

The definition of rational secondary education occurring in the prefatory memorandum is not the only guide given to schoolmasters as to the subjects which must be taught to boys taking the grant-earning course between the ages of twelve and sixteen years. In section iv. of chapter $i$. the subjects of the course are enumerated. We find :-

"The course should provide for instruction in the English language and literature, at least one language other than English, geography, history, mathematics, science and drawing, with due provision for manual work and physical exercises, and, in a girls' school, for housewifery. Not less than $4^{\frac{1}{2}}$ hours per week must be allotted to English, geography, and history; not less than $3 \frac{1}{2}$ hours to the language where only one is taken or less than 6 hours where two are taken; and not less than $7 \frac{1}{2}$ hours to science and. mathematics, of which at least three must be for science. The instruction in science must be both theoretical and practical. Where two languages other than English are taken, and Latin is not one of them, the Board will require to be satisfied that the omission of Latin is for the advantage of the school.",

Most practical schoolmasters, and men of science too if they are acquainted with the actual conditions of school work, will admit that we have outlined in these sections a rational curriculum which, in the hands of properly trained teachers, will lead to good results. We are sorry, however, to find the distinction made between theoretical and practical instruction in science; it would be better to insist simply that the time allotted to science should be devoted to experimental science. It is difficult to understand, also, why in enumerating, in section ii., the subjects of the curriculum for a course of work preparatory to that of the grant-earning years, no mention is made of science, since modern practice has demonstrated that useful preliminary work in science may be begun in the lowest forms of a secondary school.

But however admirable the regulations drawn up for the government of a secondary school, and however logical and complete the statement as to its curriculum, the success of its work in educating its pupils depends finally upon the masters to whom its work is entrusted. If these men have themselves received a broad education and have been trained for their duties along scientific lines, the boys proceeding from the school will leave it properly equipped to occupy the station to which they will be called. The training of teachers 
for any and every kind of school is, in fact, the most difficult and far-reaching of all the tasks which fall to the lot of educational administrators. A second publication of the Board of Education ${ }^{1}$ published last month assumes in consequence especial importance, and will be consulted throughout the country with the greatest interest. It is true its instructions and rules apply at present only to the preparation for their career received by teachers destined to rule in elementary schools, but it is useful as indicating the subjects which in the opinion of the Board of Education should engage the attention of the prospective teacher. Moreover, the general principles which apply to the training of teachers for elementary schools are in a large measure applicable to the professional training of their secondary school colleagues. The new regulations for the training of teachers may surely then be taken as indicating what, in the opinion of the Board of Education, should be regarded as of vital importance in any scheme for the professional preparation of every grade of teacher.

It is consequently satisfactory to find that the place of greatest prominence in the group of studies which is to engage the attention of the budding schoolmaster is given to a training in scientific method. To quote the regulations :-

"Much of the instruction which is given in all subjects must necessarily be founded upon the statements and the experience of other persons; but every education which deserves to be called complete must include some training of the student in those systematic methods of enquiry which are necessary for any assured advance in knowledge, and which are the most truly educative of all mental processes.

"If this scientific spirit is to find its right expression in the teaching given in elementary schools it must be made to imbue the whole study of the intending teacher during his course in the Training College. It must not be confined to any one branch of the curriculum. It is true that, partly as the result of tradition and partly from other reasons, the term 'scientific method' has come to be associated more particularly with the study of natural phenomena. But as a matter of fact, scientific method is of equal importance, and is indeed of ancient application, in the field of history, literature, language and philosophy; and wherever knowledge of these has made advance, it may be discerned that the essential processes of scientific enquiry have been employed.'

The specific references to the kind of instruction in science which the Board intends to encourage are deserving of even higher commendation, and if these wishes are carried into effect in the colleges in the case of each and every student in training, it will not be many years before a distinct improvement will be noticed in the teaching given in elementary schools. To refer to the regulations again :-

"But in addition to all this, and particularly in view of the courses which have for many years existed in most of the Training Colleges, a certain special regard must be given to this aspect of instruction and training, in the case of the Natural Science portions of the curriculum. It' is in this branch of study that the student can in some ways learn most effectively to depend in some measure upon his own powers, and discover that he need not take everything unverified and on trust upon the statement of text books or lecturers. For by wisely planned and supervised laboratory work the student may be brought into immediate touch with the facts of nature, and learn to find some things out for himself, and to form conclusions upon the results of his own observations. For these reasons the student's work in science should be so arranged that his experiments in the laboratory will precede and lead up to such generalisations in the formal lectures as can safely be established upon what the student has himself observed."

1 "Regulations for the Training of Teachers and for the Examination of Students in Training Colleges." [Cd.2134.] Price $4 d$. NO. I 8 I 5, VOL. 70$]$
It seems to us that the Board of Education has shown a generous appreciation of the value of scientific studies both in the professional training of teachers and in the work of the secondary school. We are promised exactly that for which men of science have frequently and consistently pleaded in these columns. It only remains now to look for the loyal cooperation of school governors and headmasters, and the reproach as to the absurdly bookish nature of English education will soon become merely a matter of history. We earnestly hope that the inspectors and other interpreters of the regulations will be inspired by the same spirit which prompted the framer of most of the sections of the prefatory memoranda to these official publications.

\section{PHYSICAL DETERIORATION.}

ELEVEN months ago the large percentage of re1. jections for physical causes of recruits for the Army led to the appointment of this committee. The members were the clerk of the council, the inspector of physical training, and the principal assistant secretary to the Board of Education, inspectors of reformatory and industrial schools and of marine recruiting, the assistant secretary of the Scotch Education Department, a representative of the General Registry Office, and a secretary.

The committee was directed "(I) to determine, with the aid of such counsel as the medical profession are able to give, the steps that should be taken to furnish the Government and the nation at large with periodical data for an accurate comparative estimate of the health and physique of the people; (2) to indicate generally the causes of such physical deterioration as does exist in certain classes; and (3) to point out the means by which it can be most effectually diminished."

This committee, composed of members of high critical faculty, has been able to focus much of the knowledge of sanitary and social science of the past generation as presented to them by wisely selected witnesses, and has evidently produced an epoch-making report.

A few items from this panorama of lives of women and children of the poorest classes may be quoted as samples of the thoroughness of this report.

While bad physique practically centres round feeding, great care has been exercised in proposing the remedies for underfed children at school, and the report states:- "Education is a great social need which individual citizens are, as a rule, not able to provide for their children on a sufficient scale, but food like clothing and lodging is a personal necessity, which in a well ordered society it is not inherently impossible for parents to provide, and the effort to supplement their deficiencies and to correct the effects of their neglect should aim in the first instance at the restoration of self-respect and enforcement of parental duty."

In the course of a full memorandum by the principal lady inspector of factories referring to employment of mothers in factories and workshops, we read:"It is impossible, however, not to be impressed by the universal preference amongst the women for factory over domestic life. I was continually being told how greatly they preferred their work in the factory to the minding of children, and how depressed and out of health they became if they were obliged to remain at home. Surprising as this appears at first, it becomes less so on consideration. At thirteen years of age the majority of these women would have begun to work in a factory, to handle their own earnings,

1 Report of the Inter-departmental Committee on Physical Deterioration. (Evre and Spottiswoode, r904.) Price is. $2 d$. 